\title{
Assessment of Citrus Susceptibility towards Candidatus Liberibacter Asiaticus-Terengganu Isolate Based on Vector and Graft Transmission Tests
}

\author{
Khairulmazmi Ahmad (Corresponding Author) \\ Department of Crop Science, Faculty of Agriculture and Food Sciences \\ Universiti Putra Malaysia Kampus Bintulu (UPMKB), 97008, Bintulu, Sarawak, Malaysia \\ E-mail:kcik@hotmail.com
}

Kamaruzaman Sijam

Department of Plant Protection

Faculty of Agriculture, Universiti Putra Malaysia (UPM)

Serdang, 43400, Serdang, Selangor, Malaysia

Habibuddin Hashim

Principal Research Officer, Biotechnology Center

Malaysian Agricultural Research and Development Institute (MARDI), Serdang

43400, Serdang, Selangor, Malaysia

Arifin Abdu

Department of Forest Management, Faculty of Forestry

Universiti Putra Malaysia (UPM), Serdang, 43400, Serdang, Selangor, Malaysia

Zamri Rosli

Department of Forestry Science, Faculty of Agriculture and Food Sciences

Universiti Putra Malaysia Kampus Bintulu (UPMKB), 97008, Bintulu, Sarawak Malaysia

Received: December 10, 2010 Accepted: December 31, 2010 doi:10.5539/jas.v3n3p159

This research project is supported by Universiti Putra Malaysia (UPM), Serdang, Selangor, Malaysia

\begin{abstract}
Five citrus species namely Citrus reticulata, C. aurantium, C. grandis, C. madurensis and Murraya paniculata were assessed for tolerance by grafting and vector transmission tests toward $\mathrm{Ca}$. L. asiaticus-Terengganu isolate. This study was conducted in an insect-proof glasshouse for a period of six months. Results of this study showed that seedlings of $M$. paniculata, and C. grandis showed no HLB symptoms six months after inoculation period. They were also showed negative results by polymerase chain reaction (PCR) test and recorded the lowest percentage of reduction rate of plant height and plant biomass. Based on our findings, proved that these two citrus species were resistance to huanglongbing (HLB) or citrus greening infection. However, C. aurantium was showed high tolerance to HLB infection with the trees exhibited mild leaf mottling and green vein and the infected seedlings recovered after 3-4 months after treated with fertilizer. However the pathogen was detected by PCR test in the recovered seedlings. C. reticulata and C. madurensis were very susceptible to HLB infection. Inoculated seedlings showed severe HLB symptoms such as leaf mottling and yellowing, leaf green vein, leaf defoliation, twigs dieback within six months after inoculation. The inoculated seedlings started showing the first symptoms within three months after inoculation. Infected seedlings were also showed positive results with PCR
\end{abstract}


test and recorded the highest percentage of reduction rate of plant height and plant biomass. Hence, this data provide a basis for developing citrus germplasm program for tolerance to HLB disease in Malaysia.

Keywords: Citrus, Candidatus Liberibacter asiaticus, Huanglongbing disease, Citrus greening

\section{Introduction}

Cirus huanglongbing (HLB) is the destructive a-proteobacteria disease of citrus in Asia, Africa, Arabic Peninsular, Mauritius Island, Madagascar (Garnier and Bove,1996) and recently in America and Brazil (Teixeira et al., 2005). Being an important disease, it affects production of citrus in several parts of Malaysia including Terengganu, which is the major producer area of citrus in Malaysia. This disease is transmitted by Asian citrus psyllid, Diaphorina citri Kuwayama. This vector was first described from Taiwan in 1907 (Pluke et al., 2005). It has been recorded in Brazil since forties (Lima, 1942) and in Malaysia in the early seventies (Lim et al., 1990). The psyllid can be found in all Southeast Asia, India, Reunion Island, Mauritious, Brazil, Saudi Arabia and Florida (da Graca, 1991; Halbert and Manjunath, 2004). In terms of host susceptibility to the HLB bacterium, the group of sweet oranges (Citrus sinensis) and mandarin (C. suhuiensis) is the most sensitive (severe) to the bacterium. On the other hand groups of lemon $(C$. lemon) and grapefruits $(C$. paradisi) are tolerance (Ahlawat, 1997). HLB symptoms are normally weakly expressed on lime (C. aurantifolia) and pummelo ( $C$. grandis) (Manicom and van Vuuren, 1990). However, very limited research was conducted to evaluate the reaction of citrus species against $\mathrm{Ca}$. L. asiaticus especially in Southeast Asian regions.

In Malaysia, HLB is considered very important disease and many programs have been conducted to control the disease spread. Reports from Department of Agriculture (DOA) showed that HLB disease has been detected in Peninsular Malaysia including Sabah and Sarawak (Azizah and Zazali, 2005). About 2458 ha or 69.7\% from 3526 ha of citrus cultivation areas in Peninsular Malaysia have been detected positive visually (Azizah and Zazali, 2005) and further study was confirmed the occurrence and spread of HLB disease in Peninsular Malaysia (Khairulmazmi et al., 2008a). In Terengganu state for example this disease was distributed widely, increasing from 641 ha in 2001 to 1262 ha in 2004 (Azizah and Zazali, 2005). This report was also showed that most of local citrus varieties or species were infected. To our knowledge, there is no study was conducted to determine pathological reaction on local citrus species against local $\mathrm{Ca}$. L. asiaticus isolates in Malaysia. $\mathrm{Ca}$. L. asiaticus-Terengganu (GFB-T) isolates was characterized based on 16S rDNA gene and it more close to Pacific area group rather than China group (Khairulmazmi et al., 2008b). Therefore, this study is intended to assess the reaction of citrus species based on two transmission tests i.e. graft and vector transmission test in order to properly manage HLB disease in Malaysia. Perhaps the data of this study provide useful insight to the managers or related agencies to develop programs for citrus germplasm program for natural tolerance to HLB disease.

\section{Materials and Methods}

\subsection{Diaphorina citri}

Adults of $D$. citri were collected from M. paniculata trees cultivated at the Universiti Putra Malaysia (UPM) Serdang, Selangor. The vector population were then maintained on M. paniculata seedlings and placed inside an insect-proof cage. The newly developed healthy adults were used in the subsequent experiments.

\subsection{Seedlings Establishment}

Seedlings of calamondin (Citrus madurensis), pummelo (C. grandis) and honey mandarin (C. reticulata) were obtained from MARDI, Cameron Highlands, Malaysia. However, sour orange $(C$. aurantium) and jasmine orange (M. paniculata) seedlings were obtained from local nurseries. The seedlings were maintained in $5 \mathrm{~L}$ $(10 \times 10 \times 35 \mathrm{~cm})$ plastic pots containing soil consisting of three parts of sand, one part of clay and one part of chicken dung mix. A foliar fertilizer (Baja Siraman NR) with essential minor elements was provided periodically. Insecticidal sprays were also carried out weekly to control leaf miner attack using Decis ${ }^{\circledR}$ (Deltametrin, Bayer, Inc.).

\subsection{Vector Transmission of GFB-T Isolate}

Four citrus species namely pummelo, sour orange and honey mandarin as well as jasmine orange were used. This study was conducted in a randomly complete block design (RCBD) consisted four blocks and three replications. A total of 100 infected adults $D$. citri were released in the middle of the study site based on free choice method. New batches of another 100 infected adults were again introduced at the same point, one week after the first introduction. The citrus seedlings were then continuously monitored and maintained inside screen house at $32 \pm^{\mathrm{O}} \mathrm{C}$ for six months for symptoms development. 
In this study data such as types of HLB symptoms, percentage of disease incidence and disease severity were measured. Percentage of disease incidence was calculated based on the number of observed symptomatic plants over the total number of the assessed plants. The below formula was used to determine percentage of disease incidence (Khairulmazmi, 2008c).

$$
\% \text { disease incidence }=\quad \frac{\text { Total infected citrus trees }}{\text { Total number of trees evaluated }} \quad \text { x } 100
$$

Percentage of disease severity was defined based on the symptom existed. The grading system as follow:

i)

ii)

iii)

iv)

$$
\begin{array}{ll}
\text { No symptom (no symptom observed on plant canopy) } & =0 \\
\text { Mild (from } 1 \text { to } 30 \% \text { of the canopy) } & =1 \\
\text { Moderate (from } 31 \text { to } 50 \% \text { of the canopy) } & =2 \\
\text { Severe (more than } 50 \% \text { of the canopy) } & =3
\end{array}
$$

The below formula was adopted to calculate percentage of disease severity;

Whereby:

$$
\% \text { disease severity }=\frac{\mathrm{X}_{1}+\mathrm{X}_{2}+\ldots .+\mathrm{Xn}}{\mathrm{Y} \text { x Maximum rating scale }} \times 100
$$

$\mathrm{X}=$ sum score of disease severity of each citrus plant

$\mathrm{Y}=$ total number of plants at the same experiment

For plant biomass measurement, every seedling was uprooted and shaken vigorously to remove the entire adhering growth medium. Root weight was measured between root crown and root tip using a mechanical balance. The plants were separated into the leaves part and roots part, the fresh weight was determined and then placed in an oven at $65^{\circ} \mathrm{C}$ for 48 hours for determination of dry weight. Plant height was measured by using a measuring tape and represented as total length from the top edge of the pot to the tallest leaf.

\subsection{Polymerase Chain Reaction Test}

Specific primers pair, composed of the forward primer of OI1 (5'-GCG CGT ATG CAA TAC GAG CGG CA-3') and reverse primer of OI2c (5'-GCC TCG CGA CTT CGC AAC CCA T-3') was used to amplify the 16S ribosomal DNA (rDNA) fragment. PCR was performed using $25 \mu 1$ of reaction mixture containing $20 \mathrm{mM}$ Tris- $\mathrm{HCl}(\mathrm{pH} 8.0), 50 \mathrm{mM} \mathrm{KCl}, 4 \mathrm{mM} \mathrm{MgCl} 2,0.2 \mathrm{mM}$ each dATP, dTTP, dCTP and dGTP, $0.5 \mathrm{mM}$ forward primer, $0.5 \mathrm{mM}$ reverse primer, 0.75 units of Taq DNA polymerase and 200ng template of nucleic acid preparation. The thermal cycle conditions were: one cycle at $95^{\circ} \mathrm{C}$ for $2 \mathrm{~min} .35$ cycles at $95^{\circ} \mathrm{C}$ for $40 \mathrm{sec}, 60^{\circ} \mathrm{C}$ for $1 \mathrm{~min}$ and $72^{\circ} \mathrm{C} 1 \mathrm{~min}$ then followed by a $72^{\circ} \mathrm{C}$ extension for $10 \mathrm{~min}$. PCR products were identified by gel electrophoresis using 1.2\% agarose (Boehringer Mannheim, Mannheim, Germany) in TBE buffer: 40mM Tris-acetate ( $\mathrm{pH} 8.0)$, 1 mM EDTA. After electrophoresis, the gel was stained with ethidium bromide $(0.5 \mu \mathrm{g} / \mathrm{ml})$ and photographed. The 1000 bp DNA Ladder set (Promega, Madison, WI, USA) was included as size markers. The electrophoresis was run for 30 to 40 min using high voltage $(100 \mathrm{~V})$.

\subsection{Graft Transmission of GFB-T Isolate}

Infected honey mandarin trees with classical symptoms of HLB disease were collected from commercial citrus growing areas in Durian Mentangau, Dungun, Terengganu. A total of twenty young citrus twigs with $10 \mathrm{~cm}$ length were collected randomly from this area. The infected twigs were then kept in transparent plastic bags and kept in cool box to maintain freshness. Citrus twigs were then used as disease inoculum for this study.

Ten seedlings of each citrus species such as sour orange, honey mandarin and pummelo and eight seedlings of calamondin were tested. Scion grafting method was used to transmit the inoculum to the healthy citrus seedlings. Each citrus seedling was inoculated with two infected scions. The inoculated seedlings were then covered with transparent plastic bag for two weeks to maintain humidity. After that, the plastic bags were removed. The citrus seedlings were then continuously monitored and maintained inside screen house at $32 \pm^{\circ} \mathrm{C}$ for six months for symptoms development. Data such as symptoms, percentage disease incidence and disease severity were evaluated. Six months post-inoculation period symptomatic and asymptomatic seedlings were tested by PCR test for confirmation of HLB infection. 


\subsection{Statistical Analysis}

Data were analyzed by using SAS ${ }^{\circledR}$ Software. Treatment effect was tested by ANOVA and the mean comparison separated by using Least Significant Different (LSD) Test at 5\% probability level.

\section{Results and Discussion}

\subsection{Reaction of Citrus Species to GFB-T Isolates}

Five citrus species namely honey mandarin, calamondin, sour orange and pummelo as well as jasmine orange were assessed on their tolerance against GFB-T isolate. In this study, we evaluated the susceptibility of citrus species against GFB-T isolate based on vector preference by free choice transmission tests and force graft transmission test.

\section{A) Vector transmission test}

HLB disease incidence on honey mandarin was $66.67 \%$ and percentage of disease severity was $70 \%$. PCR test has confirmed that only $75 \%$ of the symptomatic plants were infected by GFB-T isolate. On the other hand, no incidence of HLB disease was recorded on pummelo, sour orange and jasmine orange after 24 weeks post-inoculation period. None of the seedlings of these species were infected when tested by PCR test (Table 1 and Figure 1). Results of this study showed that free choice method by vector produced lower transmission rate as compared to graft transmission test. This result was probably due to the lower percentage of the viruliferous vector. This result is also in agreement with the previous reports which showed that percentages of disease transmission by psyllids reared on infected plants were variable. Efficiency of transmission test may vary from $1-80 \%$ for a single insect used (Xu et al., 1988). The efficiency of transmission also depends upon to the vector biotypes used. For example, the Philippine biotype is more efficient to transmit the HLB bacterium as compared to the Taiwanese biotype (Manicom and van Vuuren, 1990). Xu et al. (1988) listed several conditions that may affect transmission efficiency. These include nature of source plants, age of indicator plants, either the psyllids breed on infected plants in the laboratory or outside conditions and the environment of the greenhouse where the inocula source and indicator plants are kept. The other factors may include the pathotypes of pathogen and biotypes of vector used. This is due to the variation in populations of psyllids that may inherently acquire better transmission rate and also in populations of GFB isolates that may inherently acquire more transmissible rate and vice-versa.

The effect of HLB infection on the growth performance of four citrus species was evaluated based on the percentage reduction rate of their biomass and plant height. However, since only honey mandarin trees were infected by GFB-T isolate through free choice inoculation test, the effect of HLB infection between citrus species could not be compared. Moreover, comparison was made between the infected and non-infected seedlings of honey mandarin with respect to their biomass and plant height reduction rate. Infected honey mandarin was found to suffer severely and cause high reduction rate in the biomass of the root zone, upper root zone (stem and leaf parts) and total plant biomass with the values of $68.5 \%, 51.9 \%$ and $56.2 \%$, respectively (Table 2). Infected honey mandarin trees also recorded high reduction rate (39.4\%) of plant height.

\section{B) Graft transmission test}

Honey mandarin was highly susceptible to GFB-T isolate when compared to other citrus species tested in this method. The infected seedlings exhibited four types of HLB symptoms i.e. severe leaf mottling and yellowing, green vein, leaf defoliation and twigs dieback observed within 12-16 weeks after inoculation (Figure 2). This citrus species showed high percentage disease incidence and disease severity (Table 3). The percentage of infected seedlings was high (up to 70\%) when tested by PCR test (Figure 3).

Calamondin exhibited three types of HLB symptom; olive green symptom was observed at 12 weeks after inoculation. It was restricted to young leaves especially those close to the inoculation point. Two weeks later, another two symptoms appeared. These symptoms were severe vein yellowing and green vein. Percentage of disease incidence and disease severity were high with a value of $87.5 \%$ and $65.6 \%$, respectively.

Sour orange showed four types of HLB symptoms such as vein yellowing, green vein, mottling and mild stunting on infected seedlings. Leaf mottling symptom was intense but the other symptoms were mild. The first HLB symptom appeared at about 16 weeks after inoculation but soon it showed slight improvement. Infected seedlings started to flush with new young shoots. Disease incidence was $50 \%$ wherein infection was moderately severe (45\%). About $50 \%$ of tested plants were tested positive for the presence of GFB and most of these positive seedlings showed HLB symptom. 
No HLB symptom was observed on pummelo even after 24 weeks of post-inoculation period. The presence of GFB was also not detected by the PCR test. Based on this early study we categorized these citrus species into three groups based on their pathological reaction i.e. susceptible (honey mandarin and calamondin), tolerant (sour orange) and no response (pummelo) to the GFB-T isolate.

The susceptibly of the citrus species against GFB-T isolate ranged from no visible symptom as observed on pummelo and jasmine orange; mild infection due to recovery from infection on sour orange; and severe infection as observed on calamondin and honey mandarin. Based on this study suggested that pummelo and sour orange have potential to be used as source of resistant or tolerance genes for development of resistant variety against HLB disease. This finding agrees with the previous reports by Manicom and van Vuuren (1990) and Ahlawat (1997) which reported that sweet oranges and mandarin are more severe to HLB disease. In contrast, group of lemon and grapefruits are tolerant and limes $(C$. aurantifolia $)$ and pummelo are the most tolerant. Recent report from Brazil showed that jasmine orange is a new host for both the $\mathrm{Ca}$. L. asiaticus and $\mathrm{Ca}$. L. americanus (Lopes et al., 2005 and Lopes et al., 2006). On the other hand, there was no report in Southeast Asian region to show that jasmine orange was the natural host for $\mathrm{Ca}$. L. asiaticus. The susceptibility of hosts against plant pathogen is too complicated to understand because this event may involve many factors such as number of tolerant genes and environmental conditions that has been explained by Jin et al. (1993) and Bianchini (1999). The susceptibly was also different if the host trees were inoculated with different strains of virus (Gray et al.,1993; Ayala et al., 2002).

\section{Conclusion}

Five citrus species namely honey mandarin, sour orange, pummelo, calamondin and jasmine orange were assessed for tolerance to GFB-T isolate by graft transmission and free choice vector transmission tests. However inconsistent results were observed between these methods. For example, negative result was observed on sour orange when vector transmission test was used but positive result was obtained when graft transmission test was adopted. Jasmine orange and pummelo were found to be resistant to infection and no huanglongbing (HLB) symptom was observed even six months post-inoculation period. GFB-T isolate was also not detected in leaf tissues by polymerase chain reaction (PCR) test. Calamondin was susceptible while honey mandarin was very susceptible to HLB infection. Inoculated honey mandarin seedlings showed severe HLB symptoms such as leaf mottling and yellowing, green vein, leaf defoliation and twigs dieback. The seedlings started to show symptoms three months post-inoculation period. Infected seedlings showed positive results with PCR test. Infected honey mandarin seedlings also displayed high percentage reduction rate on their total plant biomass including root biomass and reduction of their plant height.

\section{Acknowledgement}

This project was supported by Universiti Putra Malaysia (UPM). Gratitude is expressed to Mrs Siti Mariam for technical support. We also thank MARDI and DOA for helping us in conducting the survey of huanglongbing disease in Peninsular Malaysia.

\section{References}

Ahlawat, Y. S. (1997). Viruses, greening bacterium and viroids associated with citrus (citrus species) decline in India. Indian J. Agric. Sci., 67:51-57.

Anonymous. (1999). SAS ${ }^{\circledR}$ Software. System release version 8 (TS M1), SAS Institute Trial Site, Cary, North California, USA.

Ayala L., M. Henry, M. van Ginkel, R. Sing, B. Keller and M. Khairallah. (2002). Identification of QTLs for BYDV tolerance in bread wheat, Euphytica, 128: 249-259. doi:10.1023/A:1020883414410, http://dx.doi.org/10.1023/A:1020883414410

Azizah, M. J. and Zazali, C. (2005). Status, kemerebakan dan impak penyakit greening limau terhadap industri limau di Malaysia. In bengkel kebangsaan pengurusan penyakit greening limau. Hotel Primula Beach Resort. Kuala Terengganu, Terengganu, Malaysia. 18-19 April 2005.

Bianchini, A. (1999). Resistance to bean golden mosaic virus in bean genotypes, Plant Dis., 83: 615-620. doi:10.1094/PDIS.1999.83.7.615, http://dx.doi.org/10.1094/PDIS.1999.83.7.615

da Graca, J. V. (1991). Citrus greening disease. Annu. Rev. Phytopathol, 29:109-136. doi:10.1146/annurev.py.29.090191.000545, http://dx.doi.org/10.1146/annurev.py.29.090191.000545

Garnier, M. and J. M. Bove. (1996). Distribution of the huanglongbin (greening) Liberobacter species in fifteen African and Asian countries. In Proc. $13^{\text {th }}$ Conf. IOCV, Riverside, California, pp: 388-391. 
Gray, S. M., D. Smith, and N. Atman. (1993). Barley yellow dwarf virus isolate-specific resistance in spring oats reduced virus accumulation and aphid transmission. Phytopathology, 83: 716-720. doi:10.1094/Phyto-83-716, http://dx.doi.org/10.1094/Phyto-83-716

Halbert, S. E. and Manjunath, K. L. (2004). Asian citrus psyillids (Sternorrhyncha: Psyllidae) and greening disease of citrus: A literature review and assessment of risk in Florida. Florida Entomol, 87(3):330-353. doi:10.1653/0015-4040(2004)087[0330:ACPSPA]2.0.CO;2, http://dx.doi.org/10.1653/0015-4040(2004)087[0330:ACPSPA]2.0.CO;2

Hung, T. H., M. L Wu, H. J. Su. (1999). Development of rapid method for the diagnosis of citrus greening disease using polymerase chain reaction. J. Phytopathol, 147, 599-604. doi:10.1046/j.1439-0434.1999.00435.x, http://dx.doi.org/10.1046/j.1439-0434.1999.00435.x

Jin, H., L. L. Domier, F. Kolb and C. M. Brown. (1993). Identification of quantitative loci for tolerance to barley yellow dwarf virus in oats, Phytopathology, 88: 410-415. doi:10.1094/PHYTO.1998.88.5.410, http://dx.doi.org/10.1094/PHYTO.1998.88.5.410

Khairulmazmi A, S. Kamaruzaman, H. Habibuddin, K. Jugah and S. R. Syed Omar. (2008a). Occurrence and spread of Candidatus Liberibacter asiaticus, the causal agent of huanglongbing disease of citrus in Malaysia. Res. J. Agric. \& Biol. Sci., 4(1):103-114.

Khairulmazmi A, S. Kamaruzaman, H. Habibuddin, K. Jugah and S. R. Syed Omar. (2008b). Cloning and sequencing of Candidatus Liberibacter asiaticus isolated from citrus trees in Malaysia. Int. J. Agric. Biol, 10(4):417-421.

Khairulmazmi A. (2008c). Epidemiological and molecular characterization of citrus huanglongbing disease in Malaysia. In Ph.D thesis. Faculty of Agriculture, Universiti Putra Malaysia, Serdang, Selangor, Malaysia. pp:135.

Lim, W. H., O. M. Shamsudin and W. W. Ko. (1990). Citrus greening disease in Malaysia: Status report. In Proceeding of the $4^{\text {th }}$ International Asia Pacific Conference on Citrus Rehabilitation. Chiang Mai, Thailand, 4-10 Feb. 1990. pp: 100-105.

Lima, A. M. (1942). Insectos do Brazil: Homopteros 8, Riode Janeira (Imprenso Nicional). pp: 101.

Lopes, S. A., Martin, E.C. and Frare, G. F. (2005). Deteccao de Candidatus Liberibacter americanus em Murraya paniculata. Summa Phytopathol, 31:48-49.

Lopes, S. A., Martin, E.C. and Frare, G. F. (2006). Deteccao de Candidatus Liberibacter asiaticus em Murraya paniculata. Fitopatol. Bras., 31:303.

Manicom, B. Q. and S. P. van Vuuren. (1990). Symptoms of greening disease with special emphasis on African greening. In Proc. $4^{\text {th }}$ Asian Pacific Conference on citrus rehabilitation, Chiang Mai, Thailand, 4-10 Feb 1990, pp: $127-131$.

Pluke, R. W. H., Escribano, A., Michaud, J.P. and Stansly, P. A. (2005). Potential impact of lady beetles on Diaphorina citri (Homoptera:Psyllidae) in Peuerto Rico. Florida Entomol, 88(2):123-128. doi:10.1653/0015-4040(2005)088[0123:PIOLBO]2.0.CO;2, http://dx.doi.org/10.1653/0015-4040(2005)088[0123:PIOLBO]2.0.CO;2

$\mathrm{Su}, \mathrm{H}$. J. (1998). Epidemiological review on citrus greening and viral diseases of citrus and banana with special reference to disease free nursery system. pp: 13-24. Molina, A. B., Roa, V. N., Bay-Peterson, A., Carpio, A. T., and Joven, E. A. [eds.]. In Managing banana and citrus disease. Proc. of regional workshop on disease management of banana and citrus through the use of free planting materials. Davao City, Philippines.

Teixeira D. C., Danet, J. L., Eveillard, S., Martins, E. C., Junior, W. C. D. J., Yamamoto, P. T., Lopes, S. A., Bassanezi, R. B., Ayres, A. J., Saillard, C. and J. M. Bove. (2005). Citrus huanglongbing in Sao Paulo State, Brazil: PCR detection of the Candidatus Liberibacter species associated with the disease. Mol. Cell. Probes, 19: 173-179. doi:10.1016/j.mcp.2004.11.002, http://dx.doi.org/10.1016/j.mcp.2004.11.002

Xu, C. F., Y. H. Xia, K. B. Li, and C. Ke. (1988). Further study of the transmission of citrus huanglongbin by a psyllid, Diaphorina citri Kuwayama, pp. 243-248. In L. W. Timmer, S. M. Garnsey and L. Navarro [eds] Proc. $10^{\text {th }}$ Conference of the International Organization of Citrus Virologists, Riverside, CA. 
Table 1. Reaction of three citrus species and M. paniculata against GFB-T isolate, 24 weeks after inoculation period using vector transmission test

\begin{tabular}{lcccc}
\hline Citrus Species & Inoculated Seedlings & \multicolumn{2}{c}{$\%$ Disease Incidence } & $\%$ Disease Severity \\
& & Symptoms & PCR test & \\
\hline C. reticulata & 12 & $66.67 \%$ & $75 \%$ & 70 (severe) \\
C. grandis & 12 & $0 \%$ & $0 \%$ & 0 (healthy) \\
C. aurantium & 12 & $0 \%$ & $0 \%$ & 0 (healthy) \\
M. paniculata & 12 & $0 \%$ & $0 \%$ & 0 (healthy) \\
\hline
\end{tabular}

Table 2. Dry weight, plant height and percentage of reduction rate were evaluated on infected and healthy $C$. reticulata six months post-inoculation time

\begin{tabular}{|c|c|c|c|c|}
\hline \multirow{2}{*}{ Treatments } & \multicolumn{3}{|c|}{ Biomass dry weight $(\mathrm{g})$} & Plant height \\
\cline { 2 - 4 } & Root zone & Upper root zone & Total plant & $(\mathrm{cm})$ \\
\hline Infected Seedlings & $\begin{array}{c}6.79 \mathrm{a} \\
(3.0-20.8)\end{array}$ & $\begin{array}{c}29.61 \mathrm{a} \\
(24.5-37.0)\end{array}$ & $\begin{array}{c}36.4 \mathrm{a} \\
(29.0-51.3)\end{array}$ & $\begin{array}{c}50 \mathrm{a} \\
(37-54)\end{array}$ \\
\hline Control Seedlings & $\begin{array}{c}21.6 \mathrm{~b} \\
(18-25)\end{array}$ & $\begin{array}{c}61.5 \mathrm{~b} \\
(45-78)\end{array}$ & $\begin{array}{c}83.1 \mathrm{~b} \\
(70.2-96.0)\end{array}$ & $\begin{array}{c}82.5 \mathrm{~b} \\
(80-85)\end{array}$ \\
\hline \% reduction rate & 68.5 & 51.9 & 56.2 & 39.4 \\
\hline
\end{tabular}

Figures in parenthesis are range values

Mean within a column followed by the same letters are not statistically different at $\mathrm{P} \leq 0.05$

Table 3. Reaction of four Citrus species against GFB-T isolate, 24 weeks after inoculation using graft transmission test

\begin{tabular}{|c|c|c|c|c|}
\hline Citrus species & Inoculated plant & Disease incidence (\%) & Disease severity (\% ) & $\begin{array}{c}\text { PCR test } \\
(\%)\end{array}$ \\
\hline C.reticulata & 10 & 100 & 75.5 (severe) & 70 \\
\hline C. madurensis & 8 & 87 & 65.6 (severe) & 62.5 \\
\hline C. aurantium & 10 & 50 & 45 (moderate) & 50 \\
\hline C. grandis & 10 & 0 & 0 (healthy) & 0 \\
\hline
\end{tabular}

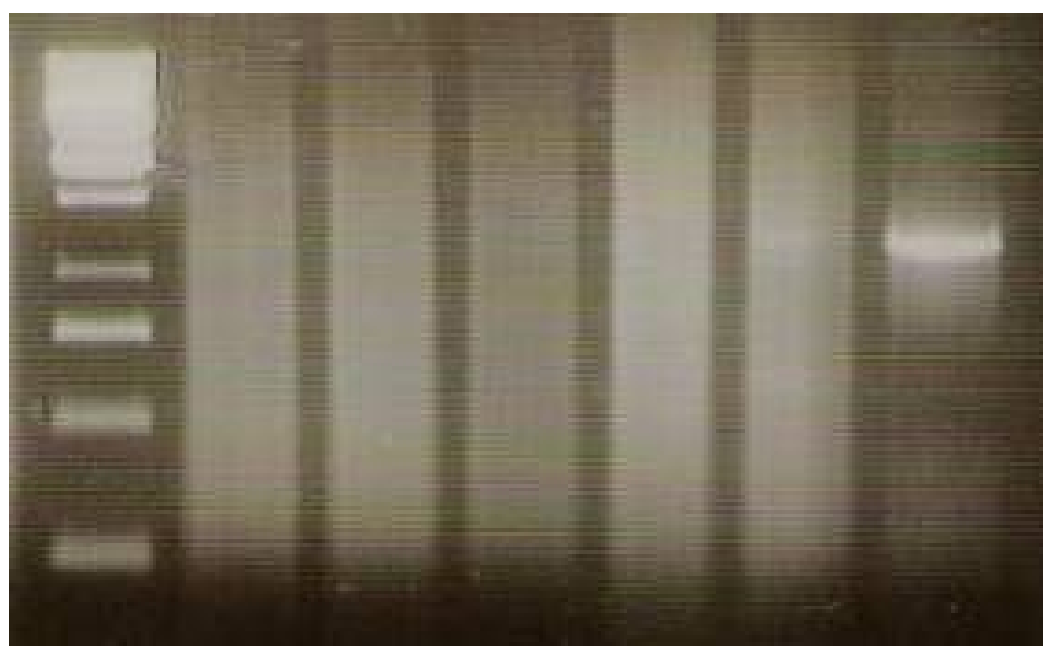

Figure 1. No amplification of $16 \mathrm{~S}$ rDNA fragment was observed on inoculated citrus seedlings 24 weeks after

Lane $1=$ Marker $1 \mathrm{~kb}$ inoculation by vector transmission test

Lane 2-3 $=C$. grandis,

Lane 4-5 $=$ M. paniculata,

Lane $6=C$. aurantium

Lane $7=$ positive control 


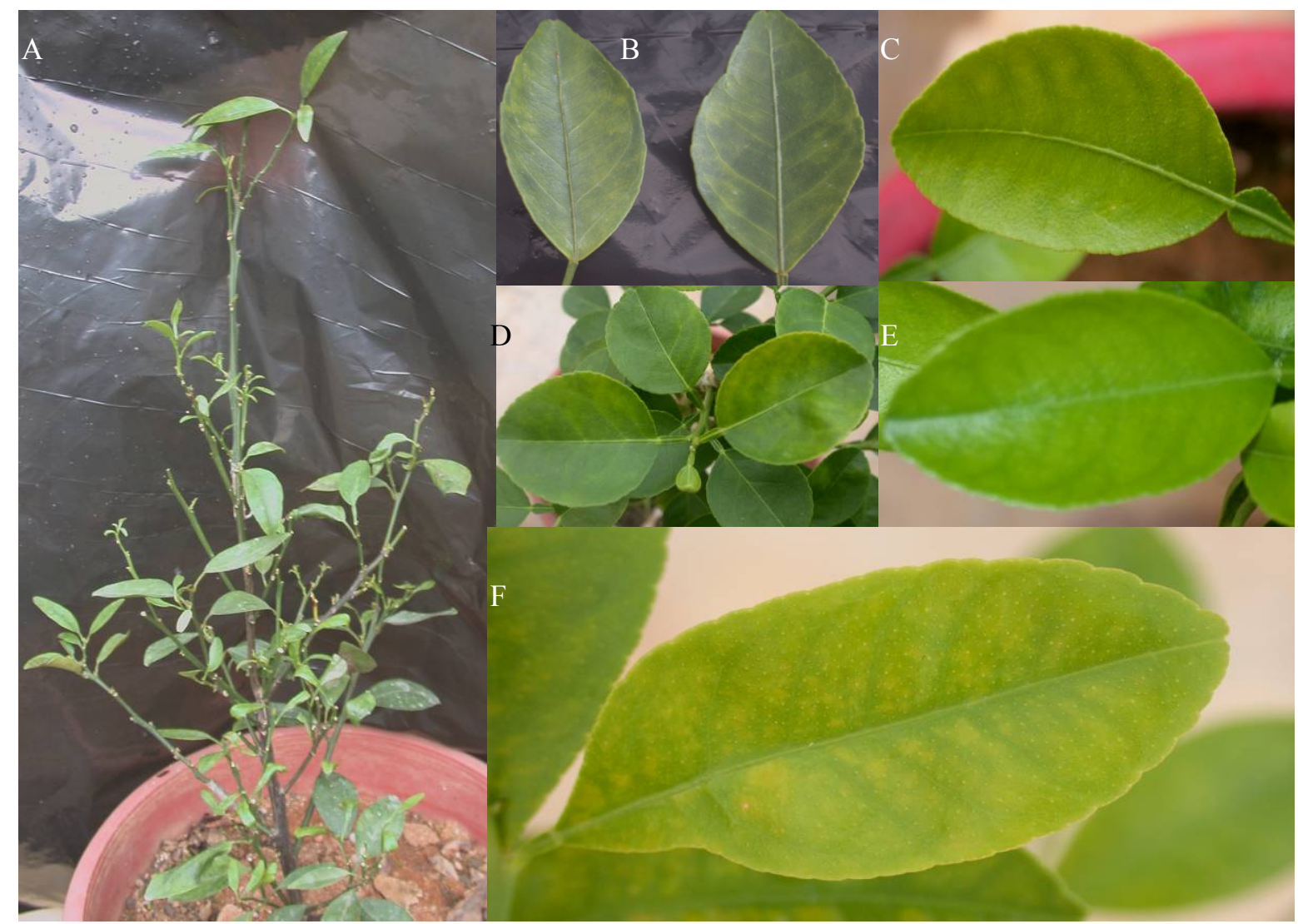

Figure 2. Symptoms of HLB disease on C. reticulata (A and B), C. madurensis (C, D, E) and C. aurantium (F) observed 12-16 weeks after inoculated with GFB-T isolates by graft transmission method: $(A)=$ Twigs dieback; $(B, D)=$ Mottling or vein yellowing; $(C, F)=$ Green vein; $(E)=$ Olive green

\section{$\begin{array}{llllllll}\text { L } 1 & \text { L2 } & \text { L3 } & \text { L4 } & \text { L5 } & \text { L6 } & \text { L7 } & \text { L8 }\end{array}$}

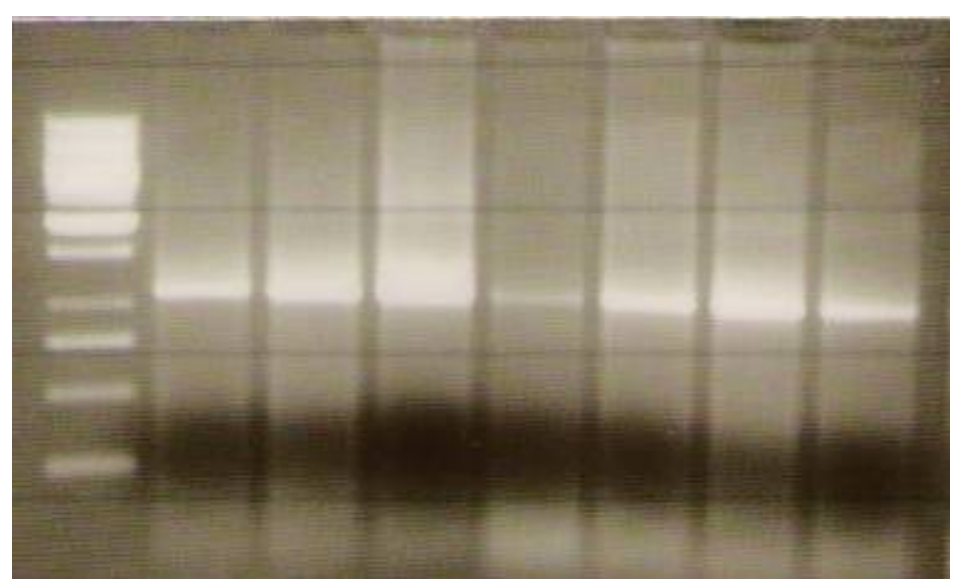

Figure 3. 16S rDNA fragments with molecular weight of 1160 bp were successfully amplified from inoculated seedlings 24 weeks after inoculation period by graft transmission test

Lane $1=$ Marker $1 \mathrm{~kb}$

Lane 2-3 $=$ C. reticulata,

Lane 4-5 = C. madurensis,

Lane $6-7=C$. aurantium

Lane $8=$ positive control 